\title{
INSTRUMENTOS E GARANTIAS PROCESSUAIS PARA O ACESSO DO IDOSO À JUSTIÇA
}

\section{INSTRUMENTS AND PROCEDURAL GUARANTEES FOR THE ELDERLY'S ACCESS TO JUSTICE}

\author{
${ }^{1}$ Ana Maria de Andrade
}

\section{RESUMO}

O estudo abordou a proteção especial e os direitos e garantias destinados aos idosos no contex to de uma sociedade que passa por um processo de envelhecimento populacional. Buscou-se avaliar os instrumentos e garantias processuais, com enfoque na criação de varas especializadas para idosos e na prioridade na tramitação processual de feitos envolvendo interesses dessa categoria de pessoas, para saber se estão sendo implementados pelos órgãos responsáveis, contribuindo para o acesso à justiça. Concluiu-se não ser possível aferir a efetividade de tais direitos por insuficiência de ações, informações e controle por parte dos órgãos questionados na pesquisa.

PALAVRAS CHAVE: Idoso; Vulnerabilidade; Acesso à Justiça; Instrumentos processuais.

\begin{abstract}
The study addressed the special protection and the rights and guarantees for the elderly in a society that is undergoing a process of population aging. The instruments and procedural safeguards were assessed, focusing on creating specialized sticks for the elderly and in compliance with the priority in proceedings involving feats of this category of interest to see if people are being implemented by the bodies responsible, contributing to access to justice. In conclusion, it is not possible to assess the effectiveness of such rights by insufficient action, information and control on the part of the agencies questioned in the survey.
\end{abstract}

KEYWORDS: Elderly; Vulnerability; Access to justice; Procedural instruments.

\footnotetext{
${ }^{1}$ Mestranda em Direito pela Universidade de Itaúna, UIT - MG, (Brasil). Advogada. E-mail: andrade.anamaria@hotmail.com.br
} 


\section{INTRODUÇÃO}

Envelhecer é um fenômeno cada vez mais natural e mundial e é um direito personalíssimo, que decorre do direito fundamental à vida e impõe ao Estado o dever de implementar as políticas públicas necessárias para oferecer condições de um envelhecimento saudável e digno (BRASIL, 2003).

Nesse sentido, o idoso brasileiro goza de proteção especial e de tratamento legal diferenciado em virtude da sua condição de vulnerabilidade inerente ao processo natural e progressivo de envelhecimento. Vários são os direitos e garantias constitucionais e legais direcionadas aos idosos, destacando-se a Lei $\mathrm{n}^{\mathrm{o}}$ 10.741/2003 (Estatuto do Idoso), como principal diploma legal de proteção aos direitos dessa categoria de pessoas.

O Estatuto do Idoso completou em outubro de 2015 doze anos de existência. Sua importância é inegável, especialmente pela evidência à necessidade de tutela diferenciada aos seus destinatários. Dentre as principais disposições nele contidas estão aquelas relacionadas ao acesso à justiça, que mereceram título próprio dentro do diploma, prevendo instrumentos e garantias processuais para efetivação desse acesso, destacando-se a possibilidade de criação de varas especializadas e exclusivas para idosos e o direito à prioridade na tramitação processual, tanto na esfera judiciária quanto administrativa.

Passados mais de dez anos dessa conquista, resta a pergunta: como anda a implementação desses direitos legalmente e constitucionalmente garantidos? Partindo-se da hipótese de há um déficit de efetivação desses direitos e considerando a relevância do tema no cenário de envelhecimento da população, este trabalho teve como objetivo geral avaliar os instrumentos e garantias processuais, com enfoque na criação de varas especializadas para idosos e no cumprimento da prioridade na tramitação processual de feitos envolvendo interesses dessa categoria de pessoas, para saber se esses estão sendo implementados pelos órgãos responsáveis, contribuindo para o acesso do idoso à justiça.

Para alcançar tal objetivo, buscou-se antes conhecer quem é o idoso tutelado pelo ordenamento jurídico; analisou-se os aspectos que levam o idoso a necessitar de proteção especial e no que consiste essa proteção, especialmente no âmbito do acesso à justiça.

Quanto à metodologia, no que diz respeito aos objetivos da pesquisa, essa se constituiu, ao mesmo tempo, em exploratória (envolvendo levantamento bibliográfico e questionário 
dirigido aos órgãos responsáveis pela implementação dos direitos dos idosos) e explicativa (a fim de identificar as condições do acesso dos idosos à justiça). No que se refere ao tipo de pesquisa, sua natureza foi qualitativa (lidando com categorias analíticas e explicativas). Optouse pelo estudo de caso como método de investigação por meio do qual se pretendeu identificar a adoção de providências para a implementação dos instrumentos e garantias processuais para o acesso dos idosos à justiça no âmbito da Comarca de Itaúna e das Prefeituras Municipais das cidades de Itaúna e Itatiaiuçu. O instrumento de coleta de dados utilizado para este estudo constituiu-se em um questionário de forma a subsidiar os dados teóricos. Tal questionário constituiu-se por interesse da pesquisadora, sendo os cenários escolhidos aleatoriamente por se tratarem de campo de estudo da pós-graduação - Mestrado em Direito da Universidade de Itaúna.

A necessidade de se buscar compreender o universo das desigualdades materiais que envolvem uma população crescente, como é o caso dos idosos, e envidar esforços para estabelecer, no plano do Direito, especialmente no que diz respeito ao acesso à justiça, condições para corrigi-las, com vistas no princípio da igualdade, justificam esta pesquisa.

\section{CONSIDERAÇÕES ACERCA DO ENVELHECIMENTO}

O envelhecimento da população é uma realidade insofismável e uma tendência mundial (BODSTEIN; BARROS, 2014; NOTARI; FRAGOSO 2011; WALTER, 2010). A previsão é que para o ano de 2025 a porcentagem de pessoas idosas some $15,1 \%$ e em 2050 alcance $21,7 \%$ da população global (NOTARI; FRAGOSO 2011). No Brasil, a população idosa poderá ultrapassar a marca de 30 milhões de pessoas em 2020, de acordo com dados do Instituto Brasileiro de Geografia e Estatística - IBGE (BRASIL, 2000) e será o sexto país do mundo em número de idosos em 2025 (WHO, 2005), sendo a longevidade justamente o principal fator definidor de seus "traços de evolução" (BRASIL, 2000, p. 10).

Embora o aumento da expectativa de vida seja uma realidade que impacta os sistemas previdenciários, a saúde pública e as configurações familiares, ela não pode ser enxergada sob uma ótica negativa, pois é reflexo de um avanço social e da melhoria das condições de vida da população (PÉREZ DÍAZ, 2003, 2005, 2006 apud WALTER, 2010).

Envelhecer é, portanto, um fenômeno cada vez mais natural e um desdobramento do elementar direito da personalidade humana. O Estatuto do Idoso (Lei $\mathrm{n}^{\circ} 10.741 / 03$, arts. $8^{\circ}$ e $9^{\circ}$ ) 
reitera o status de direito personalíssimo de envelhecer, como decorrência do direito fundamental à vida e impõe ao Estado o dever de implementar as políticas públicas necessárias para oferecer condições de um envelhecimento saudável e digno (BRASIL, 2003).

Assegurar a dignidade ao idoso, como a qualquer outro cidadão, é a mais primordial proteção aos direitos fundamentais, pois este "é o princípio vetor e o direito humano maior, que dá unidade axiológica constitucional ao sistema de outros direitos humanos fundamentais derivados dele" (BARLETTA, 2005).

\begin{abstract}
A velhice não pode mais ser encarada como uma "eventualidade" como era caracterizada essa fase da vida quando se tratava de atribuir benefícios sociais aos idosos [...] Estamos vivendo mais e necessitamos viver com dignidade, este é um dos grandes desafios que tem tensionado as agendas governamentais de todos os países do continente latino americano (SILVA; YAZBEK, 2014, p. 103).
\end{abstract}

É preciso que cultive-se a valorização e respeito pelo idoso. Ainda que sob uma perspectiva puramente egoísta, essa é uma atitude que precisa ser assumida, pois é a velhice uma realidade que alcançará a todos que sobrevivam para vivenciá-la.

\title{
1.1 Definição de idoso
}

O envelhecimento é um processo "heterogêneo e individualizado, que depende da interação entre fatores biológicos, sociais, psicológicos, econômicos, ambientais, históricos e culturais" (MASCARO, 2004, apud WALTER, 2010, p. 188), sendo assim complexo, alcançando a cada indivíduo de forma única.

O termo idoso pode ser, portanto, definido segundo diferentes critérios. Três perspectivas para a velhice podem ser citadas: a cronológica (baseada na idade) a burocrática (gera direitos a benefício, como a aposentadoria) e a psicológica (baseada em critérios subjetivos) (BOBBIO apud BRAGA, 2011).

Do ponto de vista legal, o termo idoso pode ser definido conforme os critérios cronológico (estabelecimento desta condição a partir da idade), psicobiológico (requer uma avaliação do condicionamento psicológico e fisiológico de cada indivíduo) e socioeconômico (leva em consideração a condição socioeconômica de cada indivíduo) (BRAGA, 2011).

Para a Organização Mundial da Saúde - OMS população idosa compreende os indivíduos a partir de 60 anos de idade para os países em desenvolvimento, e a partir de 65 anos 
de idade quando se trata de países desenvolvidos (GODINHO, 2010). Utiliza-se, portanto, o critério cronológico, com uma diferenciação em relação ao grau de desenvolvimento social dos países.

Embora não haja consenso quanto ao fato de a escolha do critério cronológico ser o ideal, no Brasil, com o advento da Lei no 8.842/94 (BRASIL, 1994), e posteriormente o Estatuto do Idoso (BRASIL, 2003), adotou-se esse critério para definição de idoso. Assim idoso é, para a legislação pátria, a pessoa com idade acima de 60 anos, consoante art. 60, Estatuto do Idoso (BRASIL 2003). Todavia, em alguns casos, para considerar o idoso como hipossuficiente, merecedor de certos benefícios, a lei utiliza outros critérios, como, por exemplo, no caso do artigo $3^{\circ}$, inciso V, do Estatuto do Idoso, que trata da concessão de vagas em asilos públicos, reservando-as aos idosos carentes (critério socioeconômico) (BRASIL, 2003).

\title{
1.2 Vulnerabilidade e proteção especial do idoso
}

A vulnerabilidade do idoso é uma característica advinda do processo natural e progressivo de envelhecimento.

\begin{abstract}
Para tal vulnerabilidade concorrem diversos fatores e processos - físicos, econômicos, sociais, psicológicos e fisiológicos - sendo que o declínio funcional é apontado como a principal manifestação de vulnerabilidade do idoso, revelada por uma condição de fragilidade que envolve capacidade funcional, equilíbrio e mobilidade, função cognitiva, deficiências sensoriais, condições emocionais/presença de sintomas depressivos, disponibilidade e adequação de suporte familiar e social, condições ambientais e estado e risco nutricional. (LACAS; ROCKWOOD, 2012, apud BODSTEIN et al, 2014, p. 159).
\end{abstract}

Decorre, assim, de fatores físicos, psíquicos, sociais e econômicos, exigindo do Estado uma proteção especial para haja a fruição dos direitos com igualdade em relação ao demais grupos sociais.

Ao mesmo tempo em que a sociedade foi (e vem) experimentando o aumento da expectativa de vida, paralelamente ela vivencia uma mudança nos modelos de organização social:

Se antes as famílias possuíam uma estrutura capaz de acomodar aqueles que por conta da idade não conseguiam mais desempenhar regularmente atividades produtivas, com os novos papéis impostos aos entes da família, especialmente às mulheres, os velhos perderam a garantia de acomodação certa no seio familiar (RAMOS, 2011, p. 2). 
Assim, o aumento da população idosa, associado a essa nova dinâmica de organização social, atrai o foco de atenção dos serviços públicos e da sociedade para a persecução da dignidade dessa parcela da população. A esse propósito, a Constituição Federal (art. 230) atribuiu o dever conjunto à família, à sociedade e ao Estado de amparar as pessoas idosas e assegurar-lhes uma vida digna no seio da comunidade.

Tratam-se os direitos relativos aos idosos, portanto, de direitos fundamentais de terceira geração (GOMES JUNIOR, 2005), eis que baseados nos princípios da solidariedade e fraternidade que pressupõem a união de esforços para amparar determinado grupo ou coletividade que se encontre em situação desfavorável ou de contingência.

Por tudo isso e por serem os idosos reconhecidamente portadores de vulnerabilidade, esse grupo/coletividade necessita de proteção e de tratamento legal diferenciado. Essa proteção especial dos idosos decorre também do princípio da igualdade, que impõe à lei o dever de "procurar compensar juridicamente quem sofre maiores limitações para reequilibrar suas oportunidades" (MAZZILLI, 2012, apud ZANFERDINI; NASCIMENTO JUNIOR, 2014, p. 150).

Gregório Assagra (2008, p. 546) assevera que "a tutela diferenciada e efetiva das pessoas idosas é fundamental, ainda mais num país como o nosso, onde a terceira idade sofre forte discriminação social, o que chega a ocorrer no próprio seio familiar".

Assim, o legislador constituinte cuidou de estabelecer diretrizes para assegurar a proteção dos idosos (BRASIL, 1998), conforme se depreende da leitura do art. 229 (prevê que os filhos devem ajudar e amparar os pais na velhice); do art. 230 (impõe à família, à sociedade e ao Estado o dever de amparar os idosos, assegurando-lhes participação na comunidade, defendo sua dignidade e bem-estar e garantindo-lhes o direito à vida); do art. 201, I (dispõe sobre a previdência social para a manutenção do equilíbrio financeiro e atuarial incluindo os idosos) e do art. 203, I (dispõe sobre a assistência social a ser prestada independentemente de contribuição à seguridade social). Além disso, proclamou como um dos objetivos da República Federativa do Brasil, a promoção do bem de todos, sem preconceitos de origem, raça, sexo, cor, idade e quaisquer outras formas de discriminação (art. 3º IV) (BRASIL, 1998).

No âmbito da legislação infraconstitucional, a Lei no 8.842/94 (BRASIL, 1994), foi o primeiro diploma a dispor, de forma diferenciada, sobre os direitos dos idosos.

O Estatuto do Idoso, instituído Lei $\mathrm{n}^{\circ}$ 10.741/03 (BRASIL, 2003), foi o mais importante passo dado com vistas a regular os direitos garantidos aos idosos (ALMEIDA, 2008). Esse 
instrumento prevê, dentre muitos outros direitos, certas políticas disciplinadoras do acesso à justiça pelo idoso, como será exposto no tópico seguinte.

\section{ACESSO À JUSTIÇA}

O acesso à justiça encontra, para além da proteção no plano interno, onde possui status de direito fundamental expresso no art. $5^{\circ}, \mathrm{XXXV}$ da Constituição Federal ${ }^{2}$, proteção no plano internacional, estando materializado no $\operatorname{artigo} 8^{\circ}$ da Declaração Universal dos Direitos Humanos (DUDH, 2009).

Trata-se de um direito essencial para a concretização dos demais direitos fundamentais, pois é o meio de se exigir que eles sejam efetivamente respeitados e assegurados.

Nas palavras de Maria Tereza Sadek, o acesso à justiça é um verdadeiro instrumento de inclusão social, isso porque integrar indivíduos marginalizados “em relação aos benefícios sociais gerados pelo desenvolvimento implica no seu reconhecimento como sujeitos de direitos e com possibilidades efetivas de reclamá-los" (SADEK, 2009, p. 170).

Ao longo dos anos e com as lutas travadas no seio da sociedade, conquistas importantes foram marcando a busca pela igualdade de direitos. A primeira conquista mais expressiva se deu com a passagem do absolutismo para o Estado Liberal, quando se estabeleceu a igualdade perante a lei, com o reconhecimento de direitos civis e políticos do indivíduo (primeira geração de direitos). Com o tempo, essa tônica de igualdade ia se demonstrando insuficiente e a sociedade passou a reivindicar direitos que fossem capazes de estabelecer não apenas uma a igualdade perante a lei, mas uma igualdade social, material, e foram introduzidos os direitos sociais que dependiam de uma atuação positiva do Estado para o estabelecimento da igualdade (segunda geração de direitos). Num terceiro momento, foram emergindo os direitos relativos a grupos ou coletividade (direitos de terceira geração), transcendentais aos indivíduos, no qual se enquadram, por exemplo, os direitos dos idosos. ${ }^{3}$ É certo que "o reconhecimento formal de direitos, contudo, não implica diretamente na sua efetivação" (SADEK, 2009), assim,

\footnotetext{
${ }^{2}$ Ressalte-se que tal princípio já se encontrava vigorando no ordenamento jurídico pátrio, antes da EC 45/2004 que o introduziu na $\mathrm{CF} / 88$, por força do art. 25, da Convenção Americana sobre os Direitos Humanos, tratado internacional ratificado pelo Brasil (guardando, assim, eficácia de lei federal), que já dispunha sobre esse direito. ${ }^{3}$ Vale lembrar que não necessariamente em todos os países a realização desses direitos se deu nessa ordem evolutiva e que nem sempre eles foram fruto de conquistas por lutas, mas foram outorgados.
} 
o direito ao acesso à justiça se demonstra um importante instrumento para buscar diminuir a distância entre o que a lei garante e o que é realizado.

A definição da expressão "acesso à justiça” é complexa e, segundo Cappelletti e Garth (1988, p. 8),

serve para determinar duas finalidades básicas do sistema jurídico - o sistema pelo qual as pessoas podem reivindicar seus direitos e/ou resolver seus litígios sob os auspícios do Estado. Primeiro, o sistema deve ser igualmente acessível a todos; segundo, ele deve produzir resultados que sejam individual e socialmente justos.

Ou seja o acesso à justiça deve ser efetivo e, para isso, o seu conceito deve ser lido de forma ampla, devendo compreender a condição dada ao cidadão ou coletividade não só de poder recorrer ao Judiciário, mas de obter uma prestação jurisdicional justa, que requer a transposição de certos obstáculos. Nesse sentido:

\begin{abstract}
Acesso ao Poder Judiciário e acesso à Justiça são coisas diversas. A celeridade de acesso ao Judiciário depende da parte, posto que acionar o Judiciário é seu direito. Acesso à Justiça, que corresponde a garantir a cada um o que lhe é devido, depende da atividade do Estado. A desmedida demora na prestação jurisdicional é deletéria a ambas as partes, além de ser nociva à crença no Estado de Direito, pois se não se pode confiar no aparato estatal para fazer justiça, passa-se a duvidar da validade da regra de que não se deve partir para a autotutela de direitos. (VIANNA; BIAZOTTO, 2015, p. 293)
\end{abstract}

Para a solução dos mencionados obstáculos, Cappelletti e Garth (1988) apresentam as soluções ou "ondas" representativas do movimento de busca por essa efetivação do acesso à justiça: a primeira seria a assistência judiciária; a segunda: as reformas tendentes a proporcionar representação para os interesses difusos; a terceira: é a somatória das duas primeiras, mas vai além "centra sua atenção no conjunto geral de instituições e mecanismos, pessoas e procedimentos utilizados para processar e mesmo prevenir disputas na sociedade moderna" (CAPPELLETTI; GARTH, 1988, p. 25) Assim propõem, dentre muitas outras medidas, a reforma dos procedimentos judiciais; a adoção de métodos alternativos para a solução de litígios, como juízos arbitrais, conciliação; instituições e procedimentos especiais para determinados tipos de causas de maior relevância social, especialização de instituições e procedimentos judiciais, dentre outras.

Além de ser efetivo, para que o acesso à justiça seja adequado é necessário que a decisão seja tempestiva, ou seja que "o processo disponha de mecanismos aptos a realizar a 
devida prestação jurisdicional, qual seja, de assegurar ao jurisdicionado seu direito real, efetivo, e no menor tempo possível” (ANNONI, 2007).

É nessa perspectiva que o Estatuto do Idoso traz inúmeros instrumentos e garantias para que o idoso, integrante de um grupo vulnerável que demanda do Estado medidas de proteção especial tenha garantido o acesso à justiça.

\title{
2.1 Acesso do idoso à justiça
}

A preocupação quanto ao acesso do idoso à justiça é de ordem mundial, merecendo atenção de órgãos internacionais no trato da questão:

\begin{abstract}
A preocupação mundial com o envelhecimento institucionalizou-se a partir da primeira Assembleia Mundial em 1982 que elaborou o Plano de Ação Internacional de Viena sobre o Envelhecimento considerando 63 itens que mereceram a atenção daquelas pessoas envolvidas com o evento e esses itens foram estruturados em sete grandes áreas, e uma delas é a proteção ao consumidor idoso, vislumbra-se com essa proteção o seu acesso à justiça. Em 1991, a Assembleia Geral adotou o Princípio das Nações Unidas em Favor das Pessoas Idosas, enumerando 18 direitos das pessoas idosas, e, de forma mais expressiva e significativa, no item assistência há previsão da seguinte regra "Ter acesso a serviços sociais e jurídicos que lhe assegurem melhores níveis de autonomia, proteção e assistência." Como uma vertente do acesso à justiça. (ROCHA; LIMA, 2012, p. 4)
\end{abstract}

No Brasil, acesso do idoso à justiça mereceu, no Estatuto do Idoso (Lei nº10.741/03), título próprio, apresentando normas específicas para a proteção desse grupo social.

Como instrumentos para acesso à justiça, o Estatuto prevê, em seu artigo 82, que todas as espécies de ação pertinentes são admissíveis para a defesa dos interesses e direitos dos idosos protegidos pela lei.

O diploma legal ainda prevê garantias específicas para a defesa dos direitos dos idosos, como: a) a possibilidade de aplicação, em caráter subsidiário, do procedimento sumário para conferir celeridade aos processos; b) a possibilidade de criação, pelos Tribunais, de varas especializadas e exclusivas do idoso; c) a prioridade na tramitação de processos e procedimentos tanto judiciais quanto administrativos, empresas prestadoras de serviços públicos e instituições financeiras e ao atendimento preferencial junto às defensorias em relação aos Serviços de Assistência Judiciária, e prioridade na execução de atos e diligências judiciais; d) a previsão de amplo rol de legitimados para a propositura de ações fundadas em interesses difusos, coletivos, individuais indisponíveis ou homogêneos para a defesa de seus direitos, sendo eles o Ministério Público; a União, os Estados, o Distrito Federal e os Municípios; a 
Ordem dos Advogados do Brasil; as associações legalmente constituídas há pelo menos um ano que tenham por fins a defesa dos direitos e interesses dos idosos.

Destacam-se dentre as garantias acima relacionadas, a possibilidade de criação de varas especializadas e a prioridade na tramitação processual.

Quanto à primeira garantia destacada, trata-se de uma faculdade disponibilizada aos órgãos judiciários, conforme previsão no artigo 70 do Estatuto do Idoso, que depende de políticas públicas para sua implantação. Pode-se dizer que a iniciativa para a efetivação desta garantia ainda é muito incipiente, tendo sido identificadas, no âmbito dos Tribunais brasileiros, apenas algumas varas dedicadas aos idosos, ainda assim não exclusivas, mas conjuntas com outras matérias, como é o caso do Tribunal Regional Federal da $4^{\mathrm{a}}$ Região, que implantou na cidade de Maringá a Vara Federal do Idoso e do Sistema Financeiro de Habitação - SFH (BRASIL, TRF $4^{\mathrm{a}}$ REGIÃO, on line); o Tribunal de Justiça do Estado do Rio de Janeiro, que instituiu a Vara da Infância Juventude e Idoso (BRASIL, TJRJ, on line); o Tribunal de Justiça do Estado do Amazonas, que criou a Vara especializada de Crime Contra o Idoso, Adolescentes e Crianças (BRASIL, TJAM, on line). No âmbito do Tribunal de Justiça do Estado de Minas Gerais, por exemplo, não identificou-se a existência de vara especializada e exclusiva para idosos (BRASIL, TJMG, on line).

Quanto ao direito de prioridade do idoso na tramitação processual, previsto no artigo 71 do Estatuto do Idoso, este não se trata de um privilégio, mas funda-se no princípio da isonomia (que consiste na persecução da igualdade material, estabelecendo-se mecanismos de nivelamento de forças entre desiguais):

\begin{abstract}
A prioridade de tramitação para a pessoa idosa não significa que esta seja mais digna que as demais pessoas, nem que o princípio da dignidade da pessoa humana só se aplique aos idosos. Não. Em verdade, para se entender que a relação entre prioridade de tramitação para as pessoas idosas e o primado do homem atende ao postulado da isonomia, deve-se ter presente a noção do princípio da diferença, consistente em uma distribuição que melhore a situação de todas as pessoas - trazendo benefício ao idoso que o iguale à pessoa que esteja em melhores condições de expectativa de vida -, visando a efetivar a justiça social, especialmente quando confere esperança à pessoa idosa de que seu conflito será solucionado em prazo mais curto, aumentando, assim, a efetividade do princípio da dignidade humana de forma compatível com o princípio da igualdade. (ALENCAR, 2005 apud ALCÂNTARA, 2010, p. 70)
\end{abstract}

Vale ressaltar a importância de que seja efetiva a prioridade, sob pena de se quedar-se como letra morta a disposição legal. A esse respeito 
A prioridade legalmente garantida ao idoso não pode se converter em inócuo carimbo na capa dos Autos ou, agora, em inócua anotação na página do processo eletrônico com a expressão "Prioridade - Idoso". É preciso que se dê efetividade à norma, com a criação e a implementação de mecanismos que garantam aos idosos a efetividade do acesso aos direitos materiais, com razoável duração de processos judiciais, autêntico direito de todo ser humano, que não pode ser negligenciado. (VIANNA; BIAZOTTO, 2015, p. 294)

Outro princípio constitucional justificador dessa garantia diz respeito à razoável duração do processo previsto no artigo $5^{\circ}$ LXXVII da CF/88, com reforço do Novo Código de Processo Civil que dispõe, em seu artigo $4^{\circ}$, que "as partes têm direito de obter em prazo razoável a solução integral do mérito, incluída a atividade satisfativa", e no artigo $8^{\circ}$ que "todos os sujeitos do processo devem cooperar entre si para que se obtenha, com efetividade e em tempo razoável, a justa solução do mérito".

Sendo a celeridade processual um direito que assiste a todo cidadão, com muito mais razão deve ter acesso a esse direito a pessoa idosa, que, potencialmente, possui menor tempo, em termos biológicos, para usufruir de seus direitos.

\footnotetext{
A pessoa que chegou à velhice não deve e não pode ficar esperando uma eternidade para ver o seu caso resolvido. A demora na solução, inclusive, traz sérios problemas de saúde: ansiedade, angústia, desânimo, depressão, etc. Mais do que justa é essa prioridade. (ALCÂNTARA, 2010, p. 69)
}

Para fazer jus a essa garantia, ao interessado basta requerê-la à autoridade competente, fazendo prova de sua idade com a juntada de cópia de documento de registro geral. Quanto a sua efetividade, resta saber se os órgãos responsáveis estão proporcionando-a aos interessados.

A fim de buscar elementos indicativos da efetividade ou não no cumprimento do dever de garantir prioridade na tramitação processual aos idosos, consultou-se o site do Tribunal de Justiça de Minas Gerais - TJMG, bem como órgãos da Administração Pública e o Judiciário no âmbito da Comarca de Itaúna, conforme passa-se a analisar no próximo tópico.

\section{A PRIORIDADE DO IDOSO NA TRAMITAÇÃO PROCESSUAL NO ÂMBITO DO TRIBUNAL DE JUSTIÇA DE MINAS GERAIS E DA COMARCA DE ITAÚNA}

À luz do que foi dito a respeito do efetivo acesso à justiça, buscou-se, nesse tópico, avaliar o grau de efetividade de um importante direito posto à disposição do idoso para facilitar seu acesso a uma atuação jurisdicional que atenda aos parâmetros adequados às necessidades 
específicas desta categoria social: a prioridade no trâmite processual e procedimental nos termos do Estatuto do Idoso, art. 70 e seus parágrafos.

Nesse sentido, consultou-se o site do TJMG à procura de regulamentação interna que discipline o direito de prioridade desde a distribuição, autuação, processamento, tramitação, julgamento e realização de todos os atos processuais ou procedimentais em que figure como parte ou interveniente pessoa idosa, e ainda à procura de algum mecanismo de identificação dos processos com pedido de prioridade e da existência algum procedimento de controle sobre o cumprimento ou não do direito à prioridade processual ou procedimental dos idosos.

Constatou-se a existência de disciplina normativa, por meio do Provimento $\mathrm{n}^{\mathrm{o}}$ 161/CGJ/2006, que codifica os atos normativos da Corregedoria-Geral de Justiça do Estado de Minas Gerais, onde regulamenta-se a tramitação prioritária de feitos de interesse de idosos. As disposições estão expressas no título XXV do referido instrumento normativo, porém apenas limitam-se a ratificar as disposições do Estatuto do Idoso e a determinar o atendimento prioritário nos balcões da Secretaria de Juízo e dos Serviços Auxiliares da Justiça. Ademais, apenas estabelece para o Juiz de Direito, que verificando a existência de fundamentos para o pedido de prioridade, determine à Secretaria de Juízo ou Serviço Auxiliar da Justiça as providências a serem cumpridas para o implemento desse benefício, sendo que a prioridade deverá ser anotada e destacada em local visível nos autos do processo.

Não identificou-se a existência de regulamentação de qualquer procedimento de controle sobre o cumprimento da determinação ou ainda de estatísticas levantadas sobre número de processos envolvendo idosos ou relatórios sobre o andamento processual desses feitos especificamente. Assim, não é possível aferir se as unidades judiciárias do Estado de Minas Gerais estão observando a prioridade processual para os idosos.

Para tentar identificar este controle no âmbito dos órgãos administrativos da Comarca de Itaúna, consultou-se a Diretoria do Fórum da Comarca e as prefeituras municipais das cidade de Itatiaiuçu e Itaúna, principais órgãos da Administração Pública locais, por meio de questionário contendo as seguintes questões: 1) Este órgão/instituição possui norma interna regulamentando o direito de prioridade da pessoa idosa desde a distribuição, autuação, processamento, tramitação, julgamento e realização de todos os atos processuais ou procedimentais em que figure como parte ou interveniente pessoa idosa? Em caso positivo, citar a norma; 2) Possui mecanismo de identificação dos processos com pedido de prioridade? Em caso positivo, descrevê-lo; 3) Se existe algum procedimento de controle sobre o cumprimento ou não do direito à prioridade processual ou procedimental dos idosos (estatísticas sobre o 
número de processos ou procedimentos em que figuram como parte ou interveniente pessoa idosa; estatísticas sobre tempo de duração dos processos, etc.).

Quanto ao Judiciário local, identificou-se que não há regulamentação interna quanto ao direito de prioridade na tramitação processual. $\mathrm{O}$ cumprimento à disciplina imposta pelo TJMG por meio do Provimento n 161/CGJ/2006 se dá com a marcação do processo com um carimbo indicativo de prioridade. Por fim, a unidade judiciária informou que não há procedimento de controle sobre o cumprimento ou não do direito à prioridade processual dos idosos.

No âmbito das prefeituras municipais, também não foram identificas regulamentações internas do direito de prioridade e nem um procedimento específico para identificação dos processos ou procedimentos administrativos envolvendo idosos, ou, ainda, a existência de procedimento de controle sobre o cumprimento da garantia.

Enfim, não foi possível aferir a efetividade do direito em questão, por falta de informações ou mesmo controle por parte dos órgãos consultados em relação a esse dever de cumprimento desta garantia.

\section{CONCLUSÃO}

O envelhecimento da população é uma realidade mundial que impõe um alerta para o Estado e a sociedade em geral quanto à necessidade de garantir que esse processo se dê de forma digna e saudável.

Nessa perspectiva, levando-se em consideração esse aumento da população idosa, associado a uma nova dinâmica de organização social, e à característica de vulnerabilidade própria desta categoria de pessoas, o idoso, que para a legislação brasileira é considerado como o indivíduo maior de 60 anos, adotando-se o critério cronológico para sua definição, integra um grupo de pessoas que merece justa proteção constitucional e legal especial.

O Estatuto do Idoso, principal instrumento de proteção e garantia de direitos desta coletividade, prevê, dentre muitos outros direitos, certas políticas disciplinadoras do seu acesso à justiça. Dentro de uma compreensão ampla desse termo, que passa necessariamente pelo conceito de efetividade, muitos foram os instrumentos e garantias disponibilizados aos idosos para o exercício desse direito, dentre as quais destacou-se a possibilidade de criação de varas 
especializadas para idosos no âmbito do Judiciário e o direito de prioridade na tramitação de processos e procedimentos, seja na esfera judicial ou administrativa.

Constatou-se quanto à criação de varas especializadas, que esta ainda é uma iniciativa bastante incipiente, carecendo de políticas públicas judiciárias para a sua efetivação.

Buscou-se junto ao Tribunal de Justiça de Minas Gerais - TJMG, bem como à órgãos da Administração Pública e ao Judiciário no âmbito da Comarca de Itaúna, elementos indicativos da efetividade ou não no cumprimento do dever de garantir prioridade na tramitação processual aos idosos, e concluiu-se que não é possível aferir a efetividade do direito em questão, por falta de informações ou mesmo controle por parte dos órgãos consultados em relação ao dever de cumprimento desta garantia

Por tudo o que foi dito, conclui-se por fim que, não obstante a farta legislação garantindo aos idosos amplos direitos do ponto de vista formal, especialmente quanto ao acesso à justiça, ainda há muito o que ser feito para a efetivação de tais direitos, sob pena de representar todo esse conjunto normativo meramente uma arquitetura legal simbólica.

\section{REFERÊNCIAS}

ALCÂNTARA, A. de O. Reflexões sobre o "Projeto Terceira Idade" do Tribunal de Justiça do Estado do Ceará, que regulamenta o direito de prioridade processual. R. A terceira idade. São Paulo. jul. 2010. v. 21, n. 48, p. 66-74.

ALMEIDA, G. A. de. Direito material coletivo: superação da summa divisio direito público e direito privado por uma nova summa divisio constitucionalizada. Belo Horizonte: Del Rey, 2008, 641 p.

ANNONI, D. Acesso à justiça e direitos humanos: a Emenda Constitucional 45/2004 e a garantia a razoável duração do processo. Revista Direitos Fundamentais e Democracia. Juldez. 2007. v.2, n.2.

BARLETTA F. Liberdade, igualdade e solidariedade como direitos fundamentais na democracia. Direito, Estado e Sociedade. jul-dez 2005. v.9, n.27, p. 33 a 50.

BEDIN, G. de L.; SPENGLER, F. M. O direito de acesso à justiça e as constituições brasileiras: aspectos históricos. Revista de Direitos Fundamentais e Democracia. Curitiba. Jul-dez. 2013. v. 14 , n. 14 , p. $135-146$.

BODSTEIN, A.; LIMA, V. V. A. de; BARROS, A. M. A. de. A vulnerabilidade do idoso em situações de desastres: necessidade de uma política de resiliência eficaz. Ambiente \& Sociedade. São Paulo. abr-jun 2014. v. XVII, n. 2. p. 157-174.

BRAGA, P. M. V. Curso de Direito do Idoso. São Paulo: Atlas, 2011, 138 p. 
BRASIL. Constituição da República Federativa do Brasil de 1988. Disponível em: <http://www.planalto.gov.br/ccivil_03/constituicao/constituicaocompilado.htm>. Acesso em: 01 jun. 2015.

BRASIL. INSTITUTO BRASILEIRO DE GEOGRAFIA E ESTATÍSTICA. Perfil dos idosos responsáveis pelos domicílios no Brasil 2000. Disponível em: <http://www.ibge.gov.br/home/estatistica/populacao/perfilidoso/perfidosos2000.pdf>. Acesso em: 08 jun. 2015.

BRASIL. Lei n. 8.842 de 4 de janeiro de 1994 . Disponível em: <http://www.planalto.gov.br/ccivil_03/leis/18842.htm>. Acesso em 01 jun. 2015.

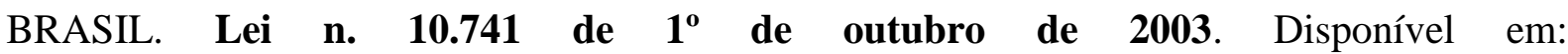
<http://www.planalto.gov.br/ccivil_03/leis/2003/110.741.htm>. Acesso em: 01 jun. 2015.

BRASIL. Lei $\mathbf{n}^{0}$ 13.105, de 16 de março de 2015. Disponível em: <http://www.planalto.gov.br/ccivil_03/_ato2015-2018/2015/lei/113105.htm>. Acesso em: 07 jun. 2016.

BRASIL, TRIBUNAL DE JUSTIÇA DO ESTADO DO AMAZONAS. Vara Especializada de Crimes Contra o Idoso, Adolescentes e Crianças. Disponível em: $<$ http://www.tjam.jus.br/index.php?option=com_contact\&view=contact\&id=100\%3Avaraespecializada-de-crimes-contra-o-idoso-adolescentes-e-criancas- \&catid=343\%3Act-cijcontatos\&Itemid=451> Acesso em: 05 dez. 2015.

BRASIL, TRIBUNAL DE JUSTIÇA DO ESTADO DE MINAS GERAIS. Provimento $\mathbf{N}^{\mathbf{0}}$ 161/CGJ/2006. Disponível em: <http://www.tjmg.jus.br/data/files/16/93/49/DA/5007A310B895B6A3180808FF/Provimento _n_161.CGJ.2006.pdf> Acesso em: 05 dez. 2015

BRASIL, TRIBUNAL DE JUSTIÇA DO ESTADO DO RIO DE JANEIRO. Vara da Infância, da Juventude e do Idoso Comarca da Capital do Estado do Rio de Janeiro Disponível em: <http://www.tjrj.jus.br/web/guest/vara-da-infancia-da-juventude-e-do-idoso1> Acesso em: 05 dez. 2015.

BRASIL, TRIBUNAL REGIONAL FEDERAL DA 4 ${ }^{\mathrm{a}}$ REGIÃO. Varas de Maringá. Disponível em<http://www2.trf4.jus.br/trf4/controlador.php?acao=pagina_visualizar\&id_pagina=289> Acesso em: 05 dez. 2015.

CAPPELLETTI, M.; GARTH, B. Acesso à Justiça. Tradução de Ellen Gracie Northfleet. Porto Alegre: Fabris, 1988, 168 p.

DECLARAÇÃO UNIVERSAL DOS DIREITOS HUMANOS - DUDH. A Declaração Universal dos Direitos Humanos. 2009. Disponível em: <http://www.dudh.org.br/wpcontent/uploads/2014/12/dudh.pdf> Acesso em: 05 dez. 2015. 
GODINHO, R. R. A proteção processual dos direitos dos idosos: Ministério Público, tutela de direitos individuais e coletivos e acesso à Justiça. $2^{a}$ ed. Rio de Janeiro: Lumen Juris, 2010, $256 \mathrm{p}$.

GOMES JUNIOR, L. M. Estatuto do Idoso - Lei Federal 10.741/2003 - aspectos processuais. Revista Fafibe On-line. Jul-2005. A. 1 - n. 1.

LEAL, R. G.; SWAROVSKY, A. As garantias constitucionais do processo no Brasil. Revista de Direitos Fundamentais e Democracia. Curitiba. Jan-jun. 2011. v. 9, n. 9, p. 242-277.

NOTARI, M. H. de A.; FRAGOSO, M. H. J. M. de M. A inserção do Brasil na política internacional de Direitos Humanos da pessoa idosa. Revista Direito GV. São Paulo. jan-jun 2011. v.7 n.1. p. 259-276.

RAMOS P. R. B. Rede de proteção e garantia dos direitos das pessoas idosas no Maranhão. Revista do Tribunal de justiça do Estado do Maranhão. Sâo Luís jul-dez. 2011. v 5, n. 2.

ROCHA, S. M. C.; LIMA, I. M. S. O. Acesso à justiça da pessoa idosa no Brasil: aspectos sociojurídicos e direitos humanos. Anais I CONINTER. 2012. Disponível em< http://www.aninter.com.br/ANAIS\%20I\%20CONITER/GT18\%20Acesso\%20\%E0\%20justi \%E7a, \%20direitos\%20humanos $\% 20 \mathrm{e} \% 20$ cidadania/ACESSO $\% 20 \% \mathrm{C} 0 \% 20 \mathrm{JUSTI} \% \mathrm{C} 7 \mathrm{~A} \% 2$ 0DA\%20PESSOA\%20IDOSA\%20NO\%20BRASIL \%20ASPECTOS\%20SOCIOJUR\%CDDI COS\%20E\%20DIREITOS\%20HUMANOS\%20-\%20Trabalho\%20completo.pdf> Acesso em 07 dez. 2015.

SADEK, M. T. A. Acesso à justiça: porta de entrada para a inclusão social. In LiVIANU, R., cood. Justiça, cidadania e democracia [online]. Rio de Janeiro: Centro Edelstein de Pesquisa Social. 2009. p. 170-180.

SILVA, M. do R. de F. e; YAZBEK, M. C. Proteção social aos idosos: concepções, diretrizes e reconhecimento de direitos na América Latina e no Brasil. Revista Katál. Florianópolis. jan./jun. 2014. v. 17, n. 1, p. 102-110.

VIANNA, L. F. H.; BIAZOTTO, P. D. O direito do idoso de acesso ao judiciário com prioridade na tramitação processual e a duração razoável e efetiva como garantia de direitos constitucionais e humanos. Anais XXIV CONPEDI, 2015. Disponível em: < http://www.conpedi.org.br/publicacoes/66fs1345/8xr5f0t5/5uBjAMc47KxE3gro.pdf>. Acesso em: 07 jun. 2016

WALTER, M. I. M. T. A dualidade na inserção política, social e familiar do idoso: estudo comparado dos casos de Brasil, Espanha e Estados Unidos. Opinião Pública. Campinas. Jun 2010. v. 16, n.1. p. 186-219

WORLD HEALTH ORGANIZATION - WHO. Envelhecimento ativo: uma política de saúde. Tradução Suzana Gontijo. Brasília: Organização Pan-Americana da Saúde, 2005. 60p.

ZANFERDINI, F. de A. M; NASCIMENTO JUNIOR, V. de F. A tutela individual e coletiva dos direitos dos idosos e a legitimidade ativa do Ministério Público. Anais do Congresso Brasileiro de Processo. Coletivo e Cidadania. Out - 2014. n. 2, p. 148-154. 
